\title{
Education for librarianship
}

\author{
STUART JOHNSTON
}

\section{Presented at the New Zealand Library Assocation Confer- ence, Hamilton, 9 February 1988}

In this paper I intend to discuss four topics: (i) the review of education for librarianship conducted by Emeritus Professor Wilfred Saunders' and initial responses to it; (ii) the context within which decisions about the future of education for your profession will have to be made; (iii) some of the principal recommendations of the report; and (iv) other leading issues arising from the report. The views in it are mine, not those of any formal group.

The Joint Advisory Committee on Librarianship (JACL) commissioned Professor Saunders to evaluate the current training programmes for librarianship in New Zealand, and to advise on the likely needs for future library and information programmes'. With the financial support of the New Zealand Library Association, the Trustees of the National Library, the British Council, Wellington Teachers College (as the Wellington College of Education was named until last month) and Victoria University of Wellington, the JACL set in train a review which has yielded a document that will be of very great significance for library studies. In a period marked by numerous reviews and reports, some of which will have limited impact because of their improvised authority, their lack of balance or their bland unwillingness to be critical, Professor Saunders' report seems to me to be an eminently helpful document, something we can work with and use as a catalyst for change. It shows the skills of a very experienced consultant; the library profession and the two teaching institutions have been very well served by Professor Saunders.

The JACL has had one meeting since the report appeared, and received reports about how it is being handled. The executive heads of the two institutions have established groups to advise on action to be taken in response to the report. The NZLA has set up an ad hoc committee to study it, and branches have begun to feed back comment and suggestions. The JACL is looking to its next meeting in April as the opportunity to pull together the responses that have been made, and to consider the views it will convey to the two institutions in pursuance of the role it has '(a) to advise the two teaching departments of manpower and training needs in librarianship in New Zealand, both for regular programmes and for short courses and seminars which may be held from time to time; (b) to provide a link for the exchange of information and views between the library profession and the two educational bodies'. The JACL has co-opted a second member of each group of teachers for 1988, and is inviting the convener of the NZLA ad hoc committee, your incoming president, to accept co-option for 1988 also.

I want to sketch in some features of the context within which the report has to be considered. Some are constantly before us, others less prominent. Perhaps the place to start in relating government policy and intentions to training for your profession is a comment in the New Zealand Market Development Board report on ed- ucation services as contributors to foreign exchange earnings. It speaks of 'the more general promotion of enterprise, innovation and flexibility in responding to changing demands which is needed throughout the New Zealand educational system'. That report says that Government should seriously consider whether any restriction based on limiting supply of qualified persons is justified or even compatible with its 'freedom of choice' objectives. Should we be seeking to expand the intakes to both librarianship programmes to satisfy the demand of all qualified applicants, and supplement the places that can be provided from government funding and subsidised fees with a market-determined number of places for New Zealand and overseas students willing to pay the full costs of their tuition? Should entry to the profession in effect be determined at the beginning of professional training, or at a later stage? If the techniques of distance education can be applied to training for your profession why not compete with other providers for a share of the wider international market for such training?

Another thrust of government policy, and one that is not likely to be a comfortable partner of the one I have just referred to, is the aim of establishing a single national validating body for all post-compulsory vocational training qualifications. This concept, which some have seen as potentially over-centralised and likely to be laborious in its workings, is being promoted at a time when there is much criticism of what has been seen as the stifling, anti-entrepreneurial and bureaucratic control of education activity in this post-compulsory sphere. If there is to be such a single national body, which would encompass the whole range of vocational qualifications under existing national authorities and presumably others as well, what should its functions be? Solely to validate qualifications, or to be responsible also for accrediting particular providers of training for those qualifications? Should all formal qualifications be issued in its name as the assessing body? If it were to have all of these responsibilities, shouldn't it also be charged with leading the development of career-long, not just initial training programmes, across the whole field, from Access-type programmes to ... .? Should some directly vocational university diploma and degree courses also be embraced by it?

Whose responsibility will it be in the future to set the standards and ensure the quality of professional preparation for librarianship? Whose task is it to sustain the quality of professional service by ongoing programmes? Should your initial professional qualifications have a limited duration, and have to be renewed at intervals? Should you have a system of registration, such as is found in many professional fields, that explicitly couples initial educational academic preparation with first appointment or probationary supervised work as the prerequisite for full professional status? As the government's intention to establish a national validating body unfolds its implications, issues such as these may have to be addressed by you.

Let me refer more briefly to the Watts Committee's review of New Zealand universities, and the establish- 
ment of the Picot Committee to review the administration of education. Both of these initiatives, as well as the Probine/Fargher report's views on the control of technical institutes, indicate that the time is ripe to give a new identity to much activity in the tertiary field. The control of teachers colleges and colleges of education is being explored. Next week in this city a meeting to discuss future university/teachers college relationships is taking place. If, as the Watts report suggests, teachers colleges become professional schools or affiliated colleges of the universities, that would have obvious implications for the relationship of the two schools of librarianship.

I know there is much more that I could introduce into this discussion to give an even stronger sense of the impossibility of considering Professor Saunders' report in isolation from everything else that is influencing tertiary education at present.

A copy is appended of the principal recommendations of the Saunders Report, grouped under headings, which I will discuss in turn:

\section{Victoria University of Wellington Department of Librarianship}

As frequently happens with such reviews, several of these recommendations pick up and endorse directions for change that were already being pursued by the Department, and the JACL expects to hear of decisions on many of the detailed curriculum points raised by Professor Saunders. A leading issue is that of the length of the diploma course. For 1988 the course is being extended by four weeks. Any further extension will depend on decisions taken about other aspects of the programme, but I think it would be timely to say that there is no enthusiasm for making the course as long as two years. I shall return to this point in my final section. Certain of the Watts Committee's remarks about the importance of developing postgraduate courses that are flexible and quickly responsive to changing needs reinforce some of Professor Saunders' recommendations.

Closer involvement with other teaching departments, especially in the information studies field, will depend on how the department exploits the fact that diploma students are a self-contained group of senior students whose teaching arrangements do not have to be tied to the timetable and conventions of most other degree and diploma programmes, in which students are spread across several departments.

\section{Wellington College of Education School of Library Studies}

Here also, an internal review of the programme had already taken hold of some of the ideas in the report, and the JACL looks forward to learning what action has been undertaken or is planned as a result of the Report. Although they do not have the same prominence in fulltime equivalent terms, the School of Library Studies students are the biggest single group of students at WCE, and the College's broadening range of programmes, as well as the presence of the school librarians' course, gives possibilities for making library studies an increasingly integral part of the work of the college.

\section{Curriculum development}

The report says that the principal need for the immediate future is the expansion of the work done in information resources management, so that the 'emerging market' for information technology can be catered for. Professor Saunders endorses the view of ANZULS ${ }^{2}$ that 'such courses should not be left totally to data processing and computer experts, unless we wish to narrow our options and downgrade the profession of librarianship'. The definition of appropriate course content, and the provision of it, from the combined resources of several university departments, will be the major academic challenge in developing the diploma course. Victoria University has recently appointed a Professor of Information Systems in the faculty of Commerce and Administration, and already has a chair in Communications. That each of these fields makes a distinctive use of the new technologies is fully recognised; Librarianship must similarly define what its distinctive teaching territory is.

\section{Distance education}

Professor Saunders has been joined by the Watts report and that of the Market Development Board in advocating the energetic expansion of distance learning, particularly in advanced and applied fields of study. Quite apart from the problems arising from some potentially diploma students taking the certificate course as their only way into the profession, there is a widespread feeling that the universities and other tertiary institutions must be more ready to diversify their training and respond more quickly to identified needs. Both the Department of Librarianship and Victoria University more generally are investigating the appropriateness to them of embarking on distance teaching.

\section{Broader issues}

The final set of recommendations I wish to address in this section of my paper are ones which raise issues of professional policy or resources that go beyond the capacity of the two departments or the JACL to resolve.

Professor Saunders prefaces his listing of 27 principal recommendations by reminding readers of his report that there are other ideas and suggestions embedded in the report. Paragraph 20 contains the most significant of these:

The Role of Training A Post-graduate Diploma programme can not stand alone and it does not in itself comprise a completely adequate professional education. There is a second and complementary element which is highly important, namely training. This is the responsibility of the employer, and the period of induction training in the first post after completing a diploma course is of very great importance. Basic professional education should in fact be seen as a partnership between the educational institution and the employer. It was clear to me that this is fully appreciated by many of New Zealand's chief librarians, who take great care to devise systematic and appropriate arrangements for training newly qualified members of staff, and also for later development training and prelibrary school training. This is, however, by no means universal, and since the matter of training is so fundamental to successful operation in times of rapid change, some systematic review of library training requirements and practice would seem to be called for. So far as I am aware no such review is under way at present.

This comment can be extended to cover the certificate course as well. In my view, the fundamental thing that has to be got right for the future is the role of these two 
initial qualifications in the whole process of professional preparation, and in the total structure of initial and inservice career development.

More and more appears to be expected of these initial academic programmes; the teachers have become more and more hard pressed; the expectation of some of the students that these initial qualifications will equip them immediately for full professional standing has brought disappointment and frustration with some aspects of the courses. In the absence of generally available complementary work-based training of the kind Professor Saunders describes, it is likely that these qualifications, as the sole group-based qualifications in librarianship, will be expected to serve an unrealistic complex of roles that makes everyone involved, students and teachers, feel they are constantly under pressure. Doubling the duration of the diploma course could be a false path to follow.

I think there is need to look at what other professions do, to identify in what ways librarianship resembles them, and in what ways it differs from them. Which groups should we be thinking of? Teachers - what can be learnt from the provision there for career-long enhancement of initial qualifications and in-service training? Whose is the overriding responsibility for sustaining the quality of work in that profession? Many categories of professionals have sophisticated requirements for certification and registration. What is it that distinguishes a professional librarian? Should the National Librarian's statutory responsibility to give advice on training for librarianship be developed into a collaborative responsibility with the profession and employers for sustaining professional standards and securing career-long and profession-wide training opportunities?

The four recommendations I have grouped as "Certificate and Diploma' have to be examined in the context I have just sketched. What is the role of the certificate, what is to be the career path of a certificate holder? As Professor Saunders says, only library managers, employers of certificate holders, not the providers, the teachers of the certificate course, can in the end determine that. Professor Saunders comments on:

the fact that with few exceptions the world of practising librarianship has given insufficient attention to job analysis and differentiation, to identifying which are those tasks and responsibilities which call for a full professional education of the type provided by a Postgraduate Diploma programme, as distinct from those which can be allocated to personnel with an intermediate qualification - i.e. the Certificate. The remedy for this lies in the hands of library managers rather than professional educationists, and I gain the impression that the present political and economic climate is likely to encourage increasingly searching scrutiny of the way in which qualified personnel are utilised in all fields of activity.

What the providers of the qualifications can seek to do is ensure that access to the courses is as flexible and unconstrained as possible. If the diploma can be offered other than on the basis of continuous residence in Wellington then it will be possible for university graduates to enter whichever programme suits them. From the responses received so far, I do not think there will be strong support for Professor Saunders' view that only in the most exceptional circumstances should university graduates be admitted to the certificate course, once access to the diploma has been improved. Some people will still want to make that personal choice, but graduates will possibly become a very small minority.

The 'ambiguous role' of the certificate - that is for the profession and employers as well as the providers of the course to work at together. I think one of the report's recommendations would spread ambiguity over both certificate and diploma: the suggestion that certificate holders should be able to convert that qualification into a diploma. Apart from the problems raised by the idea of crosscrediting into a university diploma of this scale and duration (such qualifications being expected generally to have content unique to them), there is to my mind something very unsatisfactory about linking in this way two initial qualifications with different aims and demands. As I have indicated, I think we should be looking further ahead, on into the careers of holders of both qualifications, and developing advanced qualifications that build on, and benefit from, the professional experience already gained. Professor Saunders' proposal for a Master's degree by advanced coursework comes in here. The university makes flexible provision in several of its advanced qualifications for entry by those who have 'adequate training and experience', without having the usual prerequisite degree or diploma. The Wellington College of Education has already developed a substantial programme of courses which contribute to advanced qualifications for teachers; I see no reason why similar provision could not be made for certificate holders who do not seek the new style of Master's degree. In the future collaboration of the University and College of Education it should be possible to cater for the differing needs of members of your profession for formal qualifications.

There is an obvious reason why I say 'should' rather than 'will'. So much of what Professor Saunders recommends depends upon increased resources for both programmes of study. Such resources will have to be gained in tough competition with other claimants, especially in this expanding field of vocational and post-experience education. The strong support of the profession will be needed to win those resources.

Some have seen the obvious starting point for increasing resources in the recommendation to merge the two departments into one. Professor Saunders comments on the

two separate and very small full-time staffs, each of five in number. In combination - i.e. ten full-time staff they might just about achieve critical mass for a not over-ambitious library and information studies programme. Fragmented as they are, they represent an uneconomic use of very limited staffing resources.

That phrase 'uneconomic use' has led some readers of the report to assert that there must be duplication of teaching that could be eliminated and thus free resources. When Professor Saunders speaks of the duplication of resources he is referring to resources which are currently fully committed in teaching two distinct programmes, each with its own aims, its own structure, its own pace, its own emphases. It is not the case that the target of ten full-time staff he sees as the critical mass for the diploma course would be overnight secured by a merging of the two departments. The substantial new content in information technology for which Professor Saunders argues will require additional staff with additional expertise. The model he gives for the future of the two existing programmes is one that will indeed be closely examined, but I caution against the assumption that it could be easily achieved. There is much emphasis these days on the dif- 
ferent providers in the tertiary sector doing what is appropriate to them and not encroaching on others' fields. Wellington College of Education has put a lot of energy into building up the School of Library Studies; the pattern of tuition, with periods of internal coursework alternating with practical experience, has similarities to that of other groups of students in the college; in their periods in college the library studies students have opportunities to participate in the life of a college with several hundred students that would be much less likely in a university of ten times that size.

Another model, that should be tried before it is judged to have failed, is that of collaboration between the two sets of teachers, aimed at maximising the use of the total available resources. It is indicative of the day-to-day pressures the teachers have been under that so little of this has developed. With the strong encouragement of the ViceChancellor and the Principal of the College of Education a programme of meetings of the combined staffs in the two schools has begun. A formal assocation of the two groups of teachers may evolve from this initiative, but it is much too soon to predict what form it might take. As I indicated in my opening remarks, the relationship of teachers colleges and universities is in the melting pot and librarianship is part of the brew.

The proposals for development made in the report will need to be tested and have the numbers put on them. The two institutions look to the profession for assistance in building the evidence to put with the judgements, especially evidence about the nature and scale of the 'emerging market'. If the diploma course is to be offered by distance teaching, the investment of time and other resources will have to be underpinned by careful testing of that market. In developing the case for additional resources both university and college of education must make sure that the careful analysis of the problems that has been made by Professor Saunders is matched by specific proposals for change that are buttressed by evidence that will stand up to the most searching scrutiny.

\section{The principal recommendations of the Saunders Report}

\section{Victoria University of Wellington Department of Librarianship}

- The name of the Department of Librarianship should be changed to make explicit its concern with Information Studies, and a similar change should be made in due course to the name of the School of Library Studies.

a The duration of the diploma programme should be extended, preferably to two years, which would allow the inclusion of placements in libraries; or, if this is not feasible, to some intermediate position between two years and the present length.

- The possibility of deeper and more extensive involvement of the Department of Librarianship with other teaching departments within the university should be studied.

- Changes and modifications are recommended in respect of a number of courses in the diploma programme.

- Thought needs to be given to the purpose and role of options in general and to the individual options at present on offer, in the diploma programme.
- Steps should be taken to reduce the number of assignments required of diploma students.

- A re-structuring of the diploma programme on a modular basis is recommended, with a reduction in the students' weekly lecture load to no more than twelve hours.

o The diploma programme should commence with a foundation course; and there should be additional core courses and options. A revised curriculum is suggested.

- The full-time staff of the Department of Librarianship should be increased; part-time appointments should be made; increased funding should be made available for visiting lecturers; and additional funding should be made available for staff development, retraining and exchanges. Increased funding will also be required in support of computing activity.

- The Department of Librarianship should seek to establish a position of leadership in research. Some of its research activity, at least, should be in collaboration with operational library/information systems.

\section{Wellington College of Education School of Library Studies}

- Changes and modifications are suggested in respect of a number of certificate curriculum topics.

- Recommendations are made for correcting a number of deficiencies in the present arrangements for the certificate programme.

- A review of the detailed content of all courses in the certificate programme should be carried out, with a view to reducing the extremely intensive character of the programme as it is taught at present.

- Changes should be made in the methods of teaching employed in the certificate programme.

- There should be less emphasis on examinations and assignments in the certificate programme and the whole matter of assessment should be reviewed.

o The full-time staffing complement of the School of Library Studies should be strengthened; additional funds should be made available for the employment of outside lecturers; and extra resources are required for staff development, retraining and exchanges. Increased funding in support of computing activity will also be required.

\section{Curriculum development}

- The Department of Librarianship should continue to offer an option in Archives and Records Management, if circumstances are appropriate, and the possibility of a more substantial contribution should be considered when resources permit. A study should also be made of the possibility of the School of Library Studies making a contribution to the future training of records managers.

- Serious preparation should commence for the future presentation of additional programmes of a very different character from those at present on offer - for example Information Resources Management and other programmes designed to meet the needs of the 'emerging market'.

\section{Distance education}

- The principle of offering library and information education in its various forms by the extramural distance learning route should be accepted and steps should be 
taken as quickly as possible to bring about its implementation.

- As a matter of high priority, a study should be made of the feasibility of offering alternative modes of study for the post-graduate diploma, including extramural distance teaching and short blocks of full-time study. A substantial increase should be made in the number of places available to Wellington-based students for part-time study for the Diploma.

\section{Continuing education}

- Continuing education is a matter which merits very high priority and the 1988 Workshop, under Margaret Trask's leadership, should provide a basis for future developments along the whole continuing education front.

\section{Certificate and Diploma}

- Steps should be taken to provide a means by which graduate certificate holders may convert their certificates into diplomas.

- The possibility should be explored of a Masters degree by advanced course work, with the involvement as supervisors when appropriate, of senior librarians with relevant special expertise.

- Action should be taken to resolve the present ambiguous role of the certificate.

- When satisfactory arrangements are available for graduates who wish to study for the diploma by routes other than continuous full-time study over an academic year, the certificate programme should cease to admit graduates, save in the most exceptional circumstances.

\section{Resources}

- A single, very strong department should be created to meet New Zealand's present and future needs for library and information education. As a basis for such a department such appropriate form of merger should take place between the Victoria University Department of Librarianship and the Wellington Teachers College School of Library Studies. The enlarged and strengthened department should be within the Victoria University of Wellington.

- In the run-up period to the merger the heads of the School of Library Studies and the Department of Librarianship should accord high priority to bringing about much closer working relationships between the two departments.

\section{References}

1. Wilfrid L. Saunders, An Evaluation of Education for Librarianship in New Zealand: a Report to the Foint Advisory Committee on Librarianship (Wellington, N.Z.: Dept of Librarianship, Victoria University of Wellington, 1987.

2. Association of New Zealand University Library Staff, i.e, the body responsible for negotiating conditions of employment.

Stuart Johnston is a professor of English and Assistant ViceChancellor at Victoria University of Wellington

\section{CD-ROM laser discs: the new papyrus at Porirua}

\section{STEPHEN MURPHY}

\section{Presented at the New Zealand Library Association Confer- ence, Hamilton, 9 February 1988}

As early as the first dynasty (c. 3,000 B. .) , documents were written in Egypt on a type of paper made from the pressed pith of the papyrus plant, which grew in profusion along the Nile river, where it is still cultivated today. The use of this reed revolutionised the recording of human events, and papyrus was exported from Egypt to the entire Mediterranean world, where it continued in use until at least the eleventh century A.D. In Egypt, all documents of more than passing importance, including memoranda, letters, religious, literary and scientific works, court records, oracles and architects' plans were written on papyrus. ${ }^{1}$ In 1986, the term 'new papyrus' was coined by Steve Lambert and Suzanne Ropiequet in their most comprehensive treatment of a new storage medium, the compact disc, in their Microsoft Press publication CD ROM, the New
Papyrus: the Current and Future State of the Art. ${ }^{2}$ This paper will endeavour to explain to librarians here in New Zealand the nature and possibilities of a medium which cannot help but enhance our reputation as information providers.

\section{The medium}

For those still struggling with the intricacies of the card catalogue and the difficult technique of withdrawing a stubborn catalogue drawer rod from its fittings, while balancing a pile of books and the librarian's friend, a 6-pack of Twink or Snopake in the other hand, CD-ROM is likely to sound more than a little esoteric and far-removed from their immediate needs. Since some fiction librarians might get the idea that CD-ROM is a new Mills and Boons series with the most sizzling Hollywood Wives-type bedroom scenes, some definition is probably in order right from the start. 